\title{
Investigating the Term of "Concept" In Modern Linguistics
}

\author{
Aliyeva Gunay Dilgam \\ Azerbaijan State Pedagogical University
}

\begin{abstract}
The term concept was first used by A. Aleksev. Then the term of concepts are used in different linguistic fields. In particular, concept is considered to be very important in the development of a wide range of cognitive linguistics. The concept is characterized by various types of linguists. Our studies prove that the concepts are formed in the human brain. According to the scientists in the minds of every person a concept exists as a man sees, or hears and so on. Some specific knowledge about events and things happen in the world may appear in the mind of every person who was born. While people talk, or think, or do something in any other situations concepts are exercised by them. For example, we may use some concepts in such a situation that even ourselves cannot imagine that how such kind of concept appears in our minds. Some scientists define such kinds of conceptual behavior acts a human's mind. This is a case that arose in relation to concepts in our minds.
\end{abstract}

Key words: concept, information, brain, language, idea, form, meaning

\section{INTRODUCTION}

The human brain is always in the action, and the concepts that are there are concepts. They are observed in human's behavior. N. Chomski writes about it: "The human brain from the endless amount of ideas that defines the meaning of the sentence are formed from concepts and this means that our knowledge and thoughts exist forever and endless" (Boldirev 2001, p.189). He claimed that all languages are built on the same model, but it does not mean that some languages are unmatched in the same way and the same thing which people speaking different languages and conceptual interpretation of events, or to give a description of the same kind. He noted that the creation of ideas in different languages and their development are associated with people's language skills. The scientist ( N. Chomski) also added that the idea of the creation of the human imagination is considered to be individual because each person's situation, or his behavior could be formed depending on the environment and other conditions. Any object or event, and so on are formed in person's minds according to these conditions, and if there is a change in the environment it reflects itself in the brain. (Boldirev 2001, p.190). Therefore, as we mentioned, each individual is born with a language environment is based on the language knowledge.

\section{DETERMINATION OF REFERENCE}

Mastering the language is considered to be an important factor in the formation of opinion. F.Y.Veysalli believes that language of the units is observed in a system. It is the relationship and the network of the connection of all of individuals; it is also above the individual, abstraction, social instrument. F.Y.Veysalli also states that cognitive structures are related to the idea of cognitive research reports (Veysalli 2004, p.31).

The Russian scientist E.S.Kubryakova illustrates the concepts like this: "The concept is proved to be in the memory, in mental lexicon, in the conceptual system of the brain, in the language, in the world view, and in the unit of knowledge" (Kubryakova 1977, p. 92). 
The other Russian scientist V.I.Karasik explains the term concept like this: "The concepts in human mind have been saved due to gained experiences, understanding of the mental structure of the fragments that are typically in the brain. (Karasik 2004, p.59).

I.A.Stern and Z.D.Popova have another way of approach to the problem. They wrote about the concept of the memory not thinking about it as a unit of claim. According to the scientists the main objective of the concept is to ensure the process of thinking depending on the law of the nature. The concept reflects the information in the brain, but they still need to be proved that the memory unit carries it. (Popova 2007, p. 43).

The Azerbaijani linguist F.Y.Veysalli considers concepts referring to the law of nature; the youngest of cognitive structure. Cognition system considers the function of subjective experience to be recognized in the mind units. The cognitive structures of human communication and understanding of the information have been formed according to the environmental facts (Veysalli 2015, p.32). FY.Veysalli states that the actions outside the world are formed as the man distinguishes individual objects and classes in them as far as possible to share their concepts in the brains. Identity and equivalence of signs saved in the memory of people is made possible through concepts.

It should be noted that the operation of mental concepts should be distinguished due to the laws of nature. For example, signs of phonemes, which include the concept of individual options, are formed in their supra-language units. J.A.Fodor writes that the concept must be born in the human's "thought language" (Fodor 1975, p.37).

According to some linguists the concepts are part of the "knowledge". Therefore, it is not possible to analyze concepts in their own words; information that cannot be broken down into smaller parts in the process of cognitive development can be considered units of meaning. Of course, according to structuralists the concepts of knowledge cannot be considered to be primitive because of their units.

Many authors advise to pay attention to the distinguished degree of abstraction of the concept within the conceptual traits. For example, the Russian scientist N.N.Boldirev suggests multicomponent structure that is based on the concept; he offers the core and the outer circle of his term (Boldirev 2001, p.123). The concepts of the conceptual nature of the symptoms are the result of comprehension of the concrete-figurative sense of nature and environment, in other words, to understand the usual routine of concepts can be observed due to environmental facts. Abstract concepts that form the outer circle of the signs and objects with an accuracy of distinguishing characteristics is largely theoretical, scientific and they reflect special knowledge which has been acquired because of comprehension. It should be noted that the concept of necessary part of the impairment, as well as signs of the abstract and concrete notions, as well as national, group and individual conceptual symptoms can be determined due to above-mentioned facts. The categories that the concept of cultural representatives introduces manifest itself in different ways. Nevertheless, the concept should coincide on the basis of content by placing their representatives in a whole culture and the communication between them is likely to be observed.

\section{METHODOLOGY}

One of the most important concepts of cognitive linguistics is considered to be conceptspher (konseptsfera). Conceptspher means the units of knowledge that have been formed from concepts. The term was firstly used by D.S.Likhachev (1906-1999). According to the author 
conceptspfer are the products of nation's concepts, and they are formed by basing on all potentians of the concepts of the language speakers. The richest the nation's culture, folklore, literature, art, history, experience and so on is, the richest can its concepts be. So, it is impossible to observe them being outside of these branches. Both concepts and conceptsher carry mental characters, and they cannot be observed directly. Human behavior and the brain play a significant role in the formation of human language ability. The psycholinguist Garry Markus from the University of New York has investigated the human's brain. According to him, "the brain receives the information from the senses, analyzes that information, and translates it into commands that get sent back to the muscles (Marcus 2004, p.45). This is characteristic to all brains as they were specially built to do it. There are laws of humanity to think about the brain, or create the laws that govern them. He merely says that in most cases brains' owners fed and alive and able to pass on their genes to another generation. The psycholinguist (Garry Markus) also tries to prove that brains were not formed to think about the nature of the world or the laws of nature. They only do what they have to do. According to G.Marcus the brain does its job step by step and he suggests the following ways of acting of the brain:

1. The brain receives information from senses;

2. It sends it to be analyzed for identification;

3. It chooses a course of action based on analysis;

4. It sends an order to execute that action (Marcus 2004, p.193)

One of the linguists who studies about concepts D. Bickerton does not agree with G.Marcus. He claims that the creation of the language is clear; it is fact that language occurs in the human's sense (Bickerton 2009, p.130). The brain does not perform the act that it should not do. In this case we can use a figurative expression that the brain saves energy, because it is expensive, and it does not need its own power to waste it in vain.

N. Chomski emphasized that language is at least as much a system for structuring and thinking about the world as it can be considered to be a vehicle for communication. He noted that genetic concepts are active principles, and that it does not learn everything at it, it only learns the activation process; the fact is observed in all languages, and in other cognitive processes that happen in the brain (Chomsky 1972, p.55). Any individual who was born healthy masters a language, and as the individual grows, its conceptual environment is changing, or is also growing. Here, it becomes clear that the brain, the behavior, and the thought are closely related to each other $(1, \mathrm{~s} 190)$. Individual presentation of conceptual knowledge and the knowledge of the information can be seen in each of the human. C. K. Riesbeck explains it in this way: "I understand the process of memory via cognitive method" (Riesbeck 1975, p.237).

It should be noted that consciousness, thought and intellectual concepts connected with the activity of the brain by means of a concept and conceptspher. A.A.Leontyev wrote "consciousness is a special internal movement that is formed due to the human acts, and it is the really reflection of the subject, the subject of its activities, its reflection, etc." (Veysalli 2007, p.17).

The consciousness of mind can be lined according to the following three divisions: consciousness as a phenomenon; it means: the super form of reflecting the reality; as a process; it means: the reflection of a mind; as intellect ability.

It is known that animals have also consciousness, but unlike the humans they cannot think but only behave due to their intensions. These are the points that F.Veyselli emphasizes, though 
some linguists do not argue with this issue. (Veysalli 2007, p.135). The scientists who have been carrying out experiments according to Animal Communication System have discovered some basic characteristics in this system such as they originally consider the communication behaviors that are appropriate for them to grow and respond to issues.

\section{DISCUSSION}

Some scientists claim that the core of the above-mentioned facts is the uniqueness of the language. They think that a lot of things that are related to the animals can be considered unique such as bipedalism and lack of body hair. Mammals can be given as an example. Other species have unique features too. For instance, the elephant's trunk, the giraffe's neck, the peacock's tail, etc. Woodpeckers' hammering, pit vipers' heat-sensing, ant lions trap-digging are behaviors as unique as the physical forms of elephants, giraffes, or peacocks. It is noteworthy to state that no other unique feature of any species is as isolated from the rest of evolution as language is. Let's take a look at some of the features mentioned above. For example, the lack of bipedalism is not a factor. Thus, the birds are able to do so. Another feature, the uniqueness cannot be considered as hairlessness. Thus, it can be found in some mammals. But there's one thing that's unique, that is, a review of elephants hose. The psycholinguist S.Pinker touches on the issue in his book "The Language Instinct". He uses the elephant's trunk to make language seem less of an anomaly than it really is. He put such a question: "Let's imagine what might happen if some biologists were elephants" as with language. In this case some would say the trunk was too unique to have evolved, others that it couldn't really be unique at all. Then S.Pinker insists that "a language instinct unique to modern humans poses no more of a paradox than a trunk unique to elephants." (Beckerton 2009, p.21). The linguist D.Beckerton doesn't agree with S.Pinker. He writes: "An elephant's trunk results from hyperdevelopment of the nose and adjacent parts of the face in the common ancestor of elephants and hyrax, and anatomists can point to the exact physical ingredients that went into its makeup. But of course, like other scientists S.Pinker doesn't tell us what ingredients went into the making of language. (Beckerton 2009, p.21). Thus, we can note that uniqueness is not issue, while unlikeness can be considered to be the issue. They are significant in every situation.

F.Veyselli writes that every human gets its instincts of language (words, word combinations, sentences, etc.), reflecting the outside world, thus forming a set of characters is defined as language awareness. The processes of the formation of concepts through the language of consciousness are implemented. It should be noted that, in relation to the outside world through the language of consciousness is carried out. Exchange of information and awareness of language, is carrying out an active part in the interview, the contents are sent to perform a surveillance function. But scientists claim that the language of consciousness can be interpreted as a sense of commitment to the specific language. Cognitive consciousness is connected to the outside world, and it has no other language of the status to gain.

N. Chomski didn't insist on the uniqueness of language as a whole; instead he received confirmation of the special status of recursion as the central mechanism in syntax. It is necessary to highlight that he always considered the syntax as the most main component of the language. Besides, if recursion in language could be shown to have come from recursion that had developed in a different species for a different purpose, he could continue to assert that it hadn't been selected for as a specific mechanism, which was what he'd been saying all along. N.Chomski claimed that language hadn't been selected for qua language; it was just that a whole lot of things selected for other purposes had somehow conspired to produce language. (Chomsky 1959, p.175). 


\section{CONCLUSION}

Every item concerning concept such as word, sign, sign combination, expression, etc. delivers its understanding via its meaning. Thus, we conclude that, in the opinion of linguists philosophy of language is a totally different philosophy. It has its Each of them has their own research fields. In addition, learned the meaning of linguistic philosophy, meaning their essence, image classification, and the brain can be seen reflected in the items, and as usual, it does not matter, not a matter of their naming. In fact, ancient linguists interested in this issue, and now I cannot say that this issue is fully solved.

The unity of images which are formed by means of outer factors are considered as language concsiousness. The creation of concepts in the mind is performed by means of language. It is notewortyh to mention that language also plays a very important role in connecting the mind to the outside world. The communication of information is realized through language, and the mind is open for observation. Though some scientists claim that the connection of mind to the language can be commented as language concsiencess. Cognitive mind is closely related to the outside world, and it dosn't get any other status.

\section{References}

1. Abdullayev A (2011). Actual linking, text and discourse. Baku: Zardabi LTD MMC.

2. Austin J.L (1926b). How to Do Things with Words. Cambridge: Harvard University Press.

3. Boldirev N.N (2001). Cognitive semantics: A course of lectures on English philology Tambov: Tambov Publishing house.

4. Beckerton Derek (2009). Adam's tongue. USA: New York Publishing House.

5. Chomsky N (1959). A review of B.F.Skinner's Verbal Behaviour. New York: Harcourt Brace Jovanovich.

6. Chomsky N (1972). Language and mind. Enlarged edition. New York: Harcourt Brace Jovanovich.

7. Fodor J.A (1975). The Language of theThought. Cambridge, Mass.: MIT Press.

8. Karasik V.I (2004). Introduction to Cognitive Linguistics. Moscow: Moscow Publishing House.

9. Kubryakova E.S (1977). Parts of speech with a cognitive point of view. Moscow: Moscow Publishing House.

10. Lichachev D.S (1993). Contseptsphera of the Russian language. Moscow: Ranslaya Publishing House.

11. Lyons J (2002). Linguistic Semantics: An Introduction. Cambridge: Cambridge University Press.

12. Marcus G (2004). The birth of the mind. New York: Basic Books.

13. Popova Z.D., Stepnin I.A (2007). Cognitive Linguistics. Moscow: East-west.

14. Riesbeck C.K (1975). Computational understanding, in (eds.) R.C.Schank and B.L.Nash-Webber.

15. Veysalli F.Y (2015). Cognitive Linguistics: key concepts and perspectives. Baku: Muterjim.

16. Veysalli F.Y (2007). Language. Baku: Education NPM.

\section{ABOUT AUTHOR'S BIOGRAPHY}

She was born in 1979 in Baku. She finished high school № 95 in Baku in 1996 and entered the Philological Faculty of the Azerbaijan University of Languages. She graduated from the same university with a bachelor's degree in 2000 and in the same year entered the Faculty of Linguistics of the Azerbaijan University of Languages. She graduated the master degree from the Azerbaijani University of Languages with honours diploma in 2002. She has worked as a teacher at the Department of Grammar at the Azerbaijan University of Languages since 2004. 
Since 2012 she has been teaching English at the Department of English at the Azerbaijan State Pedagogical University. More than six articles have been published at different journals by her. 